\title{
Rights and wrongs
}

\author{
Mark Doel \\ Palgrave (Macmillan Publishers Ltd), UK, 2016 \\ ISBN 978-1-137-44126-3, pp. 209, paperback, NZD50.72 (Paper Plus)
}

1 fter outlining the moral complexity in which we all live, the author

states: "What we can do, and ought to do, is construct as moral a world as possible in that part where we are moral agents. Social Workers have more opportunities than most to construct a moral world" (p. 46). Through a richly varied series of social work "dilemmas" the author invites us to engage in moral discourse. He does this by raising questions that require consideration, without himself offering answers. Doel then interrogates the original questions. This method is a time-honoured approach to ethics and provides a useful and engaging resource for social work practitioners and educators.

Early in the book, after presenting an ethical dilemma for staff in a coffee shop, Doel poses the seemingly rhetorical question: "Do you think that baristas who have studied moral philosophy will make better decisions or just slower ones?" (p. 19). Of course the same question applies to social workers and, surprisingly, this book leads me to the conclusion that it will likely make the decision-making of social workers slower, more cumbersome and not necessarily better. Perhaps this is just the first stage in our moral development as social workers? Once we become familiar and comfortable with ethical reflection, it would become easier and smoother for us to integrate it into our practice as well as our personal lives.

Whether or not we recognise it as such, social workers are constantly involved in moral discourses and decision-making. Doel's book illustrates this decision-making process eloquently with its many dilemmas. Becoming more aware of the ethical dimensions of our practice; and recognising the skills required to navigate through these dilemmas, is imperative for social workers if they are to be effective moral agents. The default position for most of us is self-interest we do what is easiest or most convenient within the pressures of our busy lives, rather than what we may think is right. While understandable, such moral laxity undermines our sense of ourselves as well as the integrity of our work. There are no quick routes to develop moral acuity. Doel's book is a good resource, especially as a tool for colleagues to reflect on moral dilemmas together, a process the author describes as the counsel of wise professionals: your inner wisdom, a supportive peer group and a good supervisor. 